\title{
The relationship between sighting dominance and the fading of a stabilized retinal image
}

\author{
CLARE PORAC \\ University of Victoria, Victoria, British Columbia, Canada \\ and \\ STANLEY COREN \\ University of British Columbia, Vancouver, British Columbia, Canada
}

\begin{abstract}
The fading of a stabilized retinal image in the sighting and the nonsighting dominant eye was studied using the Haidinger's brush target. Reaction time to the complete disappearance of the stabilized image was significantly longer when the target was input to the sighting eye. The greater persiatence of stabilized targets in the sighting eye suggests possible differences in the neural channels from the two eyes or processing differences in the two monocular channels that are related behaviorally to eye dominance.
\end{abstract}

It has been proposed that the asymmetrical use of monocular inputs, which manifests itself as eye dominance, reflects an adaptive attempt to deal with the visual confusion inherent in certain binocular viewing situations (Coren \& Duckman, 1975; Porac \& Coren, 1976, 1981). For instance, consider the common situation in which one tries to align a near target (such as an outstretched fingertip) with a distant target (such as a spot on a wall several meters away). The viewing circumstances under which this near-far alignment must be completed are those that also give rise to diplopic perception. Fixation of the distant target (the spot on the wall) causes the closer object (the fingertip) to stimulate noncorresponding retinal points and, hence, to appear as a double image. Fixation of the closer target causes the reverse situation, and the more distant target appears as a double image. The presence of diplopia during this attempted alignment should result in directional confusion, since there are now phenomenally two targets and one fingertip or two apparent fingertips and one target. The simplest solution to this diplopic problem involves restriction of the input by a shift to monocular viewing; in other words, one could close an eye. However, even with both eyes open, most observers do not experience the expected diplopia, unless sustained attention is directed to the existence of the double images. The momentary elimination of

\footnotetext{
We would like to acknowledge the assistance of Carol Behman Summerfeldt in the collection of these data. This research was supported by grants from the Natural Sciences and Engineering Research Council of Canada. It represents the equal and shared contribution of both authors. C. Porac's mailing address is: Department of Psychology, University of Victoria, P.O. Box 1700, Victoria, B.C. V8W 2Y2, Canada. S. Coren's mailing address is: Department of Psychology, University of British Columbia, Vancouver, B.C. V6T 1Y7, Canada.
}

double vision seems to occur because of the automatic operation of an eye-dominance mechanism that results in the processing of the input to one eye (the sighting dominant eye) and the simultaneous suppression of the input to the contralateral eye (the nonsighting dominant eye).

There has been a good deal of debate about the nature of eye dominance or sighting dominance, which is the type of eye dominance described above. One viewpoint contends that sighting dominance is merely a consistent behavior that is maintained by habits external to the visual system (for example, habitual pointing behaviors) and, as such, is subject to shifts as a function of the demands of the viewing situation (Barbeito, 1979; Ono \& Barbeito, 1982; Warren \& Clark, 1938). An alternate body of evidence suggests that sighting dominance is a manifestation of an underlying dominance-suppressive cooperation between the two eyes that may have important implications for an understanding of human binocular vision (Porac \& Coren, 1976, 1981). In this latter context, it has been suggested that sighting dominance behaviors in visually normal observers represent a more fleeting form of the dominance and suppressive processes found in some visual anomalies, such as amblyopia ex anopsia (Coren \& Duckman, 1975; Coren \& Kaplan, 1973; Perry \& Childers, 1972; Porac \& Coren, 1975, 1976). Porac and Coren (1978) have reported also that the sighting eye displays longer dominance times during periods of binocular rivalry, a finding that also supports the notion that eye dominance is a manifestation of monocular differences in dominance and suppression.

This second viewpoint suggests that it may be possible to predict perceptual asymmetries between the two eyes, on the basis of knowledge of an individual's sighting dominance. Specifically, if the 
binocular visual system gives preferential weighting to the input from the sighting eye (as suggested by Blake, Overton, \& Lema-Stern, 1981), then this process could manifest itself as a perceptual enhancement of that image relative to that of the contralateral eye. Data supporting this contention has been reported from a variety of different paradigms. For example, Coren and Porac (1976) have reported that there is phenomenal size enhancement of a stimulus presented to the sighting eye relative to one presented to the nonsighting eye, while Hirata (1968), Mefferd and Wieland (1969), and Mefferd, Wieland, and Dufilho (1969) have observed an overestimation of binocularly viewed stimuli presented on the side of the sighting eye. In addition, observers rate stimuli presented to the sighting eye as being phenomenally "clearer" and more saturated in color than identical stimuli presented to the nonsighting eye (Pascal, 1926; Porac \& Coren, 1981; Coren \& Porac, Note 1). The report of perceptual differences between the views of the two eyes supports the notion of processing asymmetries between the monocular channels. Although comparatively little work has been done in this area, there are also reports that information from the dominant (sighting) eye may be processed more rapidly. Such data is based on simple reaction time studies (Minucci \& Conners, 1964), simultaneity judgments (Coren \& Porac, in press), and search and recognition studies (Money, 1972; Porac \& Coren, 1979; Sampson \& Spong, 1962). Other data point to possible differences between the sighting and the nonsighting eyes that could be related to basic asymmetries in the neural substrates of the two monocular channels. For example, Wade (1976) has reported that the interocular transfer of motion aftereffects is greater when the dominant eye has been adapted, while Mikaelian and Philips (Note 2) have found similar effects for the McCulloch orientation-specific color aftereffect. Porac and Coren (1977) have noted similar asymmetrical interocular transfer for more complex perceptual effects, such as illusion decrement. Thus, the pattern of results suggests that monocular asymmetries related to eye dominance are probably central in nature, occurring at a relatively high level in the visual system.

A report by Wade (1975) provides a clue as to the nature of possible structural differences that support the perceptual asymmetries that have been described. Wade (1975) found that afterimages tended to persist for longer periods in the sighting dominant eye. Since afterimages often are considered to be equivalent to stabilized retinal projections, this result has potential theoretical importance. Stabilized retinal images have been used widely to study the involvement of basic neural mechanisms in human vision, especially the role of orientation and spatialfrequency-specific cortical units in contour percep- tion (Brown, Schmidt, Fulgham, \& Cosgrove, 1973; Cosgrove, Schmidt, Fulgham, \& Brown, 1972; Schmidt, Cosgrove, \& Brown, 1972; Schmidt, Fulgham, \& Brown, 1971; Wade, 1972, 1973a, 1973b). For this reason, the establishment of differences in the perception of stabilized retinal images in the dominant and the nondominant eyes could clarify the nature of the underlying neural substrate differences between the eyes.

Since research on this problem is relatively sparse, we conducted a study to explore the relationship between sighting dominance and the disappearance of stabilized retinal images. The afterimage procedure for the production of stabilized retinal images is, unfortunately, somewhat limited, since fragmentation effects and reappearances increase the ambiguity of the measurement of the fading time. However, since information about the relative stability of stabilized images as a function of eye dominance could elucidate structural asymmetries in the monocular channels at the cortical level, we decided to use a more precise means of image stabilization, the Haidinger's brush target.

\section{METHOD}

\section{Subjects}

Forty observers were chosen for participation based upon a set of rigorous visual and sighting dominance criteria. All were required to have uncorrected visual acuity of $20 / 30$ or better. Differences in monocular acuity within an observer were not allowed to exceed $30 \mathrm{sec}$ of arc for minimum angular resolution. All observers were also tested for normal binocular function and coordination, stereoscopically, using a Keystone Telebinocular. The sighting dominance of each participant was assessed by means of two measures, the point test and the Miles $A B C$ test. These have been shown to be good predictors of a variety of sighting dominance behaviors (Coren \& Kaplan, 1973; Coren \& Porac, 1978; Porac \& Coren, 1975, 1981). Both tests require that individuals make binocular near-far alignments while the eye used to complete the alignment is noted. Four administrations of each were used, for a total of eight trials. All participants were required to show strong sighting dominance characteristics defined as the consistent use of the same eye for sighting on at least six of the eight trials.

Based upon these criteria, 17 left-sighters $(12$ males and 5 females) and 23 right-sighters (15 males and 8 females) were selected for the final sample. All of the subjects were university students, who were paid for their participation. Each was naive as to the purpose of the experiment.

\footnotetext{
Stimulus and Apparatus

We used the Haidinger's brush as our stabilized retinal target. This entopic phenomenon, known since 1844 (see Sloan \& Naquin, 1956), can be made visible to an observer by flooding the eye with linearly polarized blue light. The accepted theory concerning its appearance suggests thiat the radially oriented crystals of the macular pigment in the foveal region absorb linearly polarized light, to a greater degree than in other areas, on the axis that is approximately perpendicular to the plane of polarization. This, in turn, causes differential illumination of the retinal cells in the foveal region (Hochheimer, 1978; Lester, 1970; Sloan \& Naquin, 1956; Stanworth \& Naylor, 1950). Under the appropriate lighting conditions, an observer will see a dark propeller or hourglassshaped figure floating against a blue field. Because an observer
} 
is viewing a structural aspect of the eye, the target is stabilized perfectly relative to eye movements, and it is centered over the macular area. The orientation of the pattern is determined by the plane of polarization of the incoming light, with the image being approximately 4 deg in projected visual angle. The Haidinger's brush target is perceived by most visually normal observers (Coren, 1971; Coren \& Kaplan, 1972; Coren \& Porac, 1974).

We used the same techniaue as that used by Coren and Porac (1974) to generate and present the brush stimulus. A sheet of flashed opal glass was illuminated from the rear by the lamp of a slide projector. We placed a Wratten No. 47 (blue) filter and a sheet of Polaroid filter (No. 328) in front of this projection screen. Both were mounted in a tube attached to a variable speed motor, and the filter apparatus was set to rotate at $60 \mathrm{cpm}$. The rotation of the plane of polarization causes the stabilized image to rotate, thus providing temporal stimulus transients that prevent the image from fading within a few seconds (see Coren, 1971). The field luminance was $171.7 \mathrm{~cd} / \mathrm{m}^{2}$, value that is within the range for maximum visibility of the brush pattern (see Coren \& Kaplan, 1972). The field of view was circular and approximately 25 deg in diameter.

\section{Procedure}

Observers were not informed about either the entopic or the stabilized nature of the Haidinger's brush stimulus. They were merely instructed to look for a small gray or black rotating propeller in the center of the projection area. Four small black dots, forming the corners of a 10-deg square, were positioned in the center of the field to assist in the maintenance of fixation in the central area. Observers were informed that the propeller figure would appear in the center of this square. In addition, observers were told to look for the propeller in the center of the square in the event that it drifted out of this viewing area.

With an opaque occluder in place over one eye, each observer monocularly viewed the projection screen through the rotating tube that held the filters. On all trials, the filters were rotated for a minimum period of $15 \mathrm{sec}$ to guarantee that the image was visible to the observer. First, the experimenter verified that the observer had the brush pattern in view. Then rotation was stopped after a predetermined random interval, completely stabilizing the image. No prestabilization rotation interval was shorter than $15 \mathrm{sec}$ or longer than $30 \mathrm{sec}$. With cessation of rotation, the stabilized image immediately begins to fade. The observer's task was to indicate that the image had disappeared completely from view by tapping a telegraph key that stopped a timer. The interval between the cessation of rotation and the depression of the telegraph key was the measure of the fading time of the stabilized target.

Because we were interested in using the stabilized image technique to explore potential differences in cortical responsiveness to the input from the sighting and the nonsighting eyes, we incorporated an additional variable into the study. Since the polarizing material must be rotated to maintain the visibility of the brush pattern beyond a period of a few seconds, we modified the apparatus so that the rotation of the polarizing material could be stopped in one of seven possible orientations. These were 0 (horizontal), 18, 36, 45, 54, 72, and 90 (vertical) deg. Thus, the fading process commenced with one of seven possible perceptual orientations of the brush target. Previous investigations of stabilized retinal image fading have reported some interactions between image orientation and time to disappearance (Atkinson, 1972; Schmidt, Fulgham, B Brown, 1971; Wade, 1972, 1973a, 1973b). These findings have been related to the orientationspecific properties of cortical units thought to be involved in the perception of contour. It seemed possible that there might be differential distributions of orientation sensitivity in the sighting vs. the nonsighting eyes; therefore, this additional variable was included in the present study.

Each observer indicated the time to disappearance of the stabilized brush pattern 70 times, 35 times with each eye. This involved five trials at each of the seven orientations. The order of eye of exposure and orientation was completely randomized on a trialby-trial basis. To control for fatigue, the observers were given frequent 5 -min rest breaks, with the total testing time being approximately $2 \mathrm{~h}$.

\section{RESULTS AND DISCUSSION}

We computed the mean fading time for each of the seven target orientations for the sighting and nonsighting eyes for each observer. Preliminary analyses revealed no significant differences between the rightand the left-eyed sighters; therefore, we collapsed the data across this variable and compared the fading times of the sighting and the nonsighting eye regardless of side. The experimental results are shown in Figure 1, which presents the mean time to disappearance as a function of eye dominance and orientation of the stabilized target.

As can be seen in the figure, when the stabilized image is presented to the sighting eye, it stays in view for a longer period of time. The image fades more quickly in the nonsighting eye in each of the seven target orientations. This overall difference in disappearance times between the sighting and the nonsighting eyes is statistically significant $[F(1,38)=$ $5.45, p<.05$ ] and is consistent with the results of Wade (1975), who reported similar differences between the sighting and the nonsighting eyes in the fading times of afterimage stimuli.

Figure 1 also seems to show a trend towards a slight increase in the length of the disappearance interval as the orientations of the stabilized image approach the vertical, or 90 deg; however, this was not a statistically significant effect, and there was no significant interaction between the eye of exposure and the final predisappearance orientation of the brush

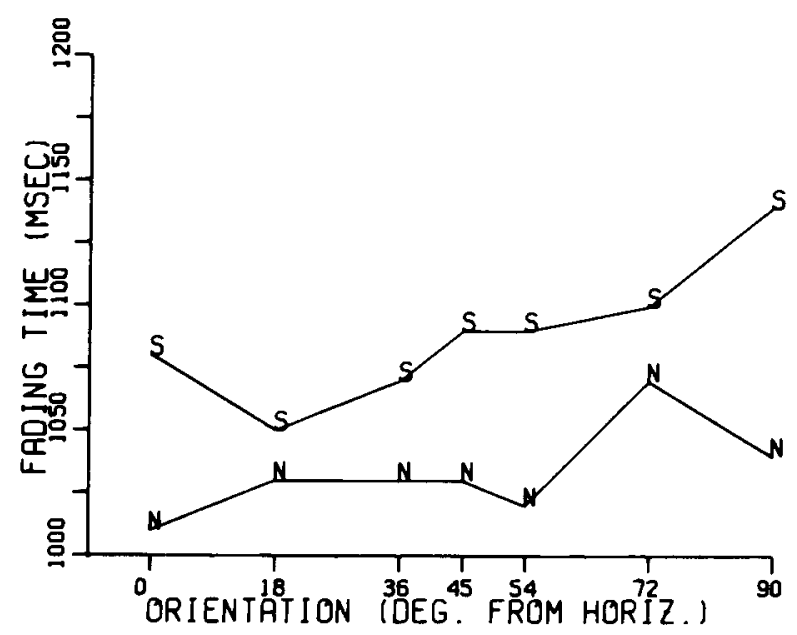

Figure 1: Time in milliseconds for the stabllized Haidinger's brush pattern to disappear completely, plotted as a function of eye of exposure ( $S$ is the sighting-dominant eye, $N$ ts the non-aightingdominant eye). Orientation refers to the angle (in degrees from the horizontal) at which the brush image censed rotation. 
stimulus. The absence of orientation-specific effects in our data contradicts the results of other studies of stabilized image fading (Brown et al., 1973; Cosgrove et al., 1972; Schmidt et al., 1972; Schmidt et al., 1971; Sharpe, 1972; Wade, 1972, 1973a, 1973b). Generally, it has been reported that horizontal and vertical lines exhibit more perceptual stability as stabilized targets than do lines of oblique orientations. Our data show a nonsignificant trend toward greater persistence only in the vertical orientation. However, Wade $(1972,1973 a)$ has also reported the absence of orientation differences in fading patterns under certain conditions. He has hypothesized that differences in the techniques used to produce stabilized targets might contribute to the presence or absence of these orientation-specific effects. Perhaps the slightly blurred nature of the brush stimulus is less effective in triggering orientation-specific mechanisms, or perhaps the slightly pinched center of the stimulus confuses the registered orientation in the visual analyzers.

The most theoretically relevant finding is that the sighting eye shows longer fading times when exposed to a stabilized retinal image stimulus than does the nonsighting eye. This result permits several theoretical interpretations, depending on the reasons presumed for the fading of stabilized retinal images. For instance, suppose that stabilized images fade as a result of the occurrence of satiation and fatigue processes at various levels of the visual system. This presumably occurs due to the absence of transient stimulation usually provided by ocular tremor and eye movements that shift the stimulus action across many receptors in a temporal sequence (see Brown et al., 1973). At the cortical level, this could refer to differences in the distribution of cells responsive to the sighting and the nonsighting eyes, or to differences in their action. Thus, Wade (1975) suggests that there may be differences in the inhibitory interactions between columns of cells representing the sighting and nonsighting eyes. Alternatively, one might argue that there is differential sensitivity or responsiveness of the cortical cells receiving input from the two eyes (Blake, Overton, \& Lema-Stern, 1981). Perhaps the simplest neural explanation is that there are greater numbers of cells responsive to the sighting eye. This would increase the probability that there are enough cells still responding at a critical level to support a visible target in the sighting eye, thus prolonging the visibility of the stabilized image in its channel. This latter suggestion also might explain the observed phenomenal differences in the apparent salience of images in the sighting and the nonsighting eyes (Coren \& Porac, 1976; Porac, 1975; Porac \& Coren, 1981; Coren \& Porac, Note 1), and the increased speed of response in the sighting eye (Coren \& Porac, in press; Minucci \& Conners, 1964).
While these neural explanations seem to have some apparent cogency, one must not rule out the pos-1 sibility that the relative resistance to fading of the stabilized retinal image displayed by the sighting eye could reflect cognitive, rather than physiological factors. There have been suggestions that the inputs to the sighting eye seem to gain some priority in attention (Davson, 1949; Money, 1972; Porac \& Coren, 1977; Sampson \& Spong, 1962), and some reports suggest that higher level processing may be a factor in the disappearance of stabilized retinal images (Coren \& Porac, 1974).

Although we cannot ascertain an exact causal mechanism, these results do show that there are asymmetries in the two monocular channels that are predictable from a knowledge of an individual's eye dominance ascertained using simple sighting tests. These asymmetries are detectable in more complex perceptual coordinations. In particular, the sighting eye seems to show greater perceptual stability than the nonsighting eye in that stabilized retinal images presented to it are more resistant to fading.

\section{REFERENCE NOTES}

1. Coren, S., \& Porac, C. Eye signature: Phenomenal differences as a function of sighting dominance. Paper presented at the meeting of the Psychonomic Society, Phoenix, Arizona, November 1979.

2. Mikaelian, H. H., \& Philips, M. Orientation-specific aftereffects. Paper presented at the meeting of the Psychonomic Society, San Antonio, Texas, November 1978.

\section{REFERENCES}

Atkinson, J. The effect of size, retinal locus, and orientation on the visibility of a single afterimage. Perception \& Psychophysics, 1972, 12, 213-217.

BARBE ITO, R. Ocular dominance: An explanation based on sighting behaviors. Unpublished doctoral dissertation, York University, 1979.

Blake, R., Overton, R., \& Lema-Stern, S. Interocular transfer of visual aftereffects. Journal of Experimental Psychology: Human Perception and Performance, 1981, 7, 367-381.

Brown, D. R., Schmidt, M. J., Fulgham, D. D., \& Cosgrove, M. P. Human receptive field characteristics: Probe analysis of stabilized images. Vision Research, 1973, 13, 231-244.

Conen, S. The use of Haidinger's brushes in the study of stabilized retinal images. Behavior Research Methods \& Instrumentation, 1971, 3, 295-297.

CoREn, S., \& DuCKman, R. H. Ocular dominance and amblyopia. American Journal of Optometry and Physiological Optics, $1975,52,47-50$.

CoRen, S., \& KaPlan, C. P. Clarity of Haidinger's brushes as a function of luminance. Behavior Research Methods \& Instrumentation, 1972, 4, 341-342:

Conen, S., \& Kaplan, C. P. Patterns of ocular dominance. American Journal of Optometry and Archives of the American Academy of Optometry, 1973, 50, 283-292.

Coren, S., \& Porac, C. The fading of stabilized images: Eye movements and information processing. Perception \& Psychophysics, 1974, 16, 529-534. 
Coren, S., \& Porac, C. Size accentuation in the dominant eye. Nature, 1976, 260, 527-528.

Conen, S., \& Porac, C. The validity and reliability of self-report items for the measurement of lateral preference. British Journal of Psychology, 1978, 69, 207-211.

Coren, S., \& Porac, C. Monocular asymmetries in visual latency as a function of sighting dominance. American Journal of Optometry and Physiological Optics, in press.

Cosonove, M. P., Schmidt, M. J., Fulgham, D. D., \& Brown, D. R. Stabilized images: Dependent variable specificity of patternspecific effects with prolonged viewing. Perception \& Psychophysics, 1972, 11, 398-402.

Davson, H. The physiology of the eye (1st ed.). London: Churchill, 1949.

Hirata, K. Experimental study on right-left problems in visual balance. Psychologia, 1968, 11, 139-142.

Hochheimer, B. F. Polarized light retinal photography of a monkey eye. Vision Research, 1978, 18, 19-23.

Lester, G. Haidinger's brushes and the perception of polarization: The history to the present of an on-going problem. Acta Psychologica, 1970, 34, 106-114.

MEFFERd, R. B., \& W IELAND, B. Influence of eye dominance on the apparent centers of simple horizontal lines. Perceptual and Motor Skills, 1969, 28, 847-850.

Mefferd, R. B., Wieland, B., \& Dufilho, L. P. Systematic alterations of the apparent centers of lines. Perceptual and Motor Skills, 1969, 28, 803-825.

Minucci, P. K., \& Conners, M. M. Reaction time under three viewing conditions: Binocular, dominant eye, and nondominant eye. Journal of Experimental Psychology, 1964, 67, 268-275.

Monex. J. Studies on the functioning of sighting dominance. Quarterly Journal of Experimental Psychology, 1972, 24, 454-464.

Ono, H., \& Barberto, R. The cyclopean eye vs. the sightingdominant eye as the center of visual direction. Perception Psychophysics, 1982, 32, 201-210.

Pascal, J. I. The chromatic test for the dominant eye. American Journal of Ophthalmology, 1926, 9, 357-358.

Perry, N. W., \& Childers, D. G. Monocular contribution to binocular vision in normals and amblyopes. In G. B. Arden (Ed.), The visual system: Neurophysiology, biophysics and their clinical applications. New York: Plenum Press, 1972.

Porac, C. Ocular dominance and suppressive processes in binocular vision (Doctoral dissertation, Graduate Faculty of the New School for Social Research, 1974). Dissertation Abstracts International, 1975, 35, 4229b. (University Microfilms No. 75-2323).

Porac, C., \& Conen, S. Suppressive processes in binocular vision: Ocular dominance and amblyopia. American Journal of Optometry and Physiological Optics, 1975, 52, 651-657.

Porac, C., \& Coren, S. The dominant eye. Psychological Bulletin, 1976, 93, 880-897.
Porac, C., \& Coren, S. The assessment of motor control in sighting dominance using an illusion decrement procedure. Perception \& Psychophysics, 1977, 21, 341-346.

Porac, C., \& Coren, S. Sighting dominance and binocular rivalry. American Journal of Optometry and Psychological Optics, 1978, 55, 208-213.

Porac, C., \& Coren, S. Monocular asymmetries in recognition after an eye movement: Sighting dominance and dextrality. Perception \& Psychophysics, 1979, 25, 55-59.

Porac, C., \& Coren, S. Lateral preferences and human behavior. New York: Springer-Verlag, 1981.

Sampson, H., \& Srong, P. Handedness, eye-dominance, and immediate memory. Quarterly Journal of Experimental Psychology, 1962, 13, 173-180.

Schmidt, M. J., Cosgrove, M. P., \& Brown, D. R. Stabilized images: Functional relationships among populations of orientation-specific mechanisms in the human visual system. Perception \& Psychophysics, 1972, 11, 389-392.

Schmidt, M. J., Fulgham, D. D., \& Brown, D. R. Stabilized images: The search for pattern elements. Perception \& Psychophysics, 1971, 10, 295-299.

SHARPE, C. R. The visibility and fading of thin lines visualized by their controlled movement across the retina. Journal of Physiology, 1972, 222, 113-134.

Sloan, L. L., \& Naquin, H. A. A quantitative test for determining the visibility of the Haidinger's brushes: Clinical applications. American Journal of Ophthalmology, 1956, 40, 393-406.

Stanworth, A.. \& Naylor, E. J. Haidinger's brushes and the retinal receptors with a note on the Stiles-Crawford effect. British Journal of Ophthalmology, 1950, 34, 282-291.

WAdE, N. J. Orientation effects on line afterimages. Perception \& Psychophysics, 1972, 12, 409-416.

WADE, N. J. Orientation and spatial frequency effects on linear afterimages. Perception \& Psychophysics, 1973, 13, 446-450. (a)

WADE, N. J. Orientation and spatial frequency effects on linear afterimages: The retinal reference for selectivity-A supplementary report. Perception \& Psychophysics, 1973, 14, 384-386. (b)

WADE, N. J. Fragmentation of monocular afterimages in individuals with and without normal binocular vision. Perception \& Psychophysics, 1975, 18, 328-330.

WADE, N. J. On interocular transfer of the movement aftereffect in individuals with and without normal binocular vision. Perception, 1976, 5, 113-118.

Warren, N., \& Clark, B. A consideration of the use of the term ocular dominance. Psychological Bulletin, 1938, 35, 298-304.

(Manuscript received March 1, 1982;

revision accepted for publication August 16, 1982.) 